\title{
Papillary, Follicular, Hurthle Cell, Poorly Differentiated, and Anaplastic Thyroid Carcinoma cNOb TNM Finding v8
}

National Cancer Institute

\section{Source}

National Cancer Institute. Papillary, Follicular, Hurthle Cell, Poorly Differentiated, and Anaplastic Thyroid Carcinoma cNOb TNM Finding v8. NCI Thesaurus. Code C140905.

No radiologic or clinical evidence of locoregional lymph node metastasis. (from AJCC 8th Ed.) 